Article

\title{
Stochastic Unit Commitment Problem, Incorporating Wind Power and an Energy Storage System
}

\author{
Khalid Alqunun ${ }^{1, *}$, Tawfik Guesmi ${ }^{1,2}$, Abdullah F. Albaker ${ }^{1}$ and Mansoor T. Alturki ${ }^{1}$ \\ 1 Department of Electrical Engineering, University of Ha'il, Ha'il 2240, Saudi Arabia; \\ tawfik.guesmi@istmt.rnu.tn (T.G.); af.albaker@uoh.edu.sa (A.F.A.); m.alturki@uoh.edu.sa (M.T.A.) \\ 2 National Engineering School of Sfax, University of Sfax, Sfax 3038, Tunisia \\ * Correspondence: kh.alqunun@uoh.edu.sa
}

Received: 18 October 2020; Accepted: 30 November 2020; Published: 3 December 2020

\begin{abstract}
This paper presents a modified formulation for the wind-battery-thermal unit commitment problem that combines battery energy storage systems with thermal units to compensate for the power dispatch gap caused by the intermittency of wind power generation. The uncertainty of wind power is described by a chance constraint to escape the probabilistic infeasibility generated by classical approximations of wind power. Furthermore, a mixed-integer linear programming algorithm was applied to solve the unit commitment problem. The uncertainty of wind power was classified as a sub-problem and separately computed from the master problem of the mixed-integer linear programming. The master problem tracked and minimized the overall operation cost of the entire model. To ensure a feasible and efficient solution, the formulation of the wind-battery-thermal unit commitment problem was designed to gather all system operating constraints. The solution to the optimization problem was procured on a personal computer using a general algebraic modeling system. To assess the performance of the proposed model, a simulation study based on the ten-unit power system test was applied. The effects of battery energy storage and wind power were deeply explored and investigated throughout various case studies.
\end{abstract}

Keywords: wind power; energy storage systems; unit commitment; stochastic optimization; modeling; simulation

\section{Introduction}

\subsection{Research Background and Related Works}

Conventional power networks with one direction of power transferred from the supply side to the demand side have created many concerns related to technical and economic risks. Moreover, thermal power generators are commonly associated with harmful carbon emissions and are highly dependent on fossil fuel consumption. Therefore, modern power networks that allow the deployment of renewable energy sources and the transfer of bidirectional power have been introduced to meet these concerns. In fact, renewable energy resources, such as wind turbines, were introduced to relieve the aforementioned concerns and to provide the network system with a sufficient rate of reliability and a low operation cost. Indeed, in 2018, the total installed wind power capacity worldwide was 591 Gigawatts and increased to 650 Gigawatts by the end of 2019 [1]. Despite the several advantages provided by wind turbines, it is challenging to control their operation due to the intermittency and fluctuation nature of wind generation. For instance, high wind power (WP) penetration can impact the power system reliability and stability, since this kind of resource is non-dispatchable; its power generation depends on the speed of the surrounding wind, which is uncontrollable [2,3]. Thus, today's power system operators extended the classical models of several problems in order to consider the 
intermittency of WP [4]. The unit commitment problem (UCP) of wind energy has been one of the most studied problems over the last few years [5-8]. The UCP aims to determine which units have to be committed/uncommitted from an economic perspective [9]. The production levels of committed units must be found in order to meet the predicted load at a minimum total production cost over a planning horizon, varying from one day to one week. In general, most of the operation costs include start-up costs and shut-down costs [10]. The minimization of the operating costs is affected by several operating constraints, which can lead to a limitation of the search space. Power balance constraints, generation limits, spinning reserve constraints, minimum up-time/down-time constraints, unit initial status, and ramp rate limits of units are the most used constraints in UCP formulations [11]. Decision variables for the UCP consist of both states of units, which are based on binary/integer variables that represent the status of units (" 1 " when the unit is "ON" and " 0 " when the unit is "OFF") and the output power of the committed units, which are continuous/real variables. For a long time, the UCP has been mainly formulated as a mixed-integer optimization problem [11] and its complexity depends on the power network dimension. If the number of units grows, the number of combinations of 0 and 1 increases exponentially. Due to the intermittency of WP, there are some effects on the power system, such as the unsatisfactory correlation between the variation of the load and WP. Energy storage systems (ESSs), such as flywheels, pumped hydro storage, compressed air storage, hydrogen storage with the fuel cell, and battery energy storage systems (BESSs), are mostly used to handle this correlation [12,13]. Essentially, ESSs are coordinated with thermal generators and renewable energy sources in order to capture and store excess energy during the off-peak period and discharge it at the peak period.

In recent years, the incorporation of ESSs and/or renewable sources has been investigated for several power system applications [14-16]. Integrating wind turbines with BESSs is one of the most useful techniques for regulating wind turbine power, which is widely discussed in the literature [17-19]. In [12], a comparison between battery storage and hydrogen storage was investigated and it showed that BESS can provide the best performance and achieve the highest self-sufficiency ratio and net present value. The fast wind-induced power variation was smoothed by integrating a short-term energy storage system into a doubly-fed induction generator in [20]. Moreover, the ability of the storage system to improve the transient performance of wind turbine generators was investigated. In [21], a fuzzy logic-based frequency controller for wind farms integrated with ESSs to improve the frequency response in low-inertia power systems was proposed. Moreover, the offered fuzzy logic-based frequency controller could be reinforced, optimally using stored energy in the ESS and generated power from wind farms by minimizing the required storage capacity and eliminating the inflexible de-loading, respectively. A Lead Acid Battery model and its integration into a stand-alone wind energy system during wind speed variation were presented and analyzed in [22]. In addition, a control method for monitoring the voltage and the battery state of charge in order to realize the maximum power characteristic of wind turbines was investigated. In [23], the impact of the wind forecast uncertainty on the value of stored energy in the United Kingdom future was investigated, addressing the economic and technical impacts of reserves in ESSs. In [24], a coordinated operational dispatch scheme for wind farms integrated with BESSs was proposed, where the offered scheme aims to reduce the impacts associated with wind power forecast errors while expanding the lifetime of utilized BESSs. The proposed scheme involves two stages, optimal planning and operation stages, where the optimal power and energy capacity of the BESS (based on the historical data of wind power) and the optimal power dispatch of the wind farm and the BESS were determined, respectively. In [25], a stochastic optimization method for optimal sizing of a hybrid power system involving renewable energy resources and an energy storage system was presented, while taking the reliability requirements of the hybrid power system into account. In addition, it applied the Monte Carlo simulation method to generate data in a time sequence in order to determine reliability indices from the simulated experiments. In [26], a stochastic framework for boosting the operability and reliability of integrated wind energy systems was proposed by utilizing ESSs. In order to optimally size and place the energy storage system, a genetic algorithm optimization, as well as a probabilistic optimal power 
flow, were utilized. The planning and operation of wind farms integrated with ESSs in electricity markets were investigated in [27], where the proposed methodology aims to define the energy delivery of the combined system that better fits the generation forecast. A model for the economic evaluation of a hybrid system that involves wind power and hydro pumped storage was presented in [28], where development of the electricity price uncertainty and market effects have been taken into account. The impact of the use of fast-acting storage in providing dynamic frequency control support for an isolated island (the French island of Guadeloupe) that integrates renewable energy resources based on dynamic simulations was investigated in [29]. Control methodologies of integrated grid-scale battery energy storage systems in supporting wind energy were presented in [30]. They demonstrated the impact of the battery energy storage system on improving the overall system operation and efficiency. The reliability of generating systems that involve WP and ESS using the Monte Carlo simulation technique was evaluated in [31]. They presented a realistic energy storage system model that includes various system stability and operational constraints, and demonstrated its impact on the integrated system. The study proposed in [32] investigated the ability to make wind farms more dispatchable by integrating a BESS, where it developed a control strategy based on an open-loop optimal control scheme that optimally controls the use of the battery energy storage system, taking into account its operating constraints.

Even though various works have studied the integration of ESSs and WP into power systems, the simultaneous incorporation of these devices in the UCP and the power dispatch problem has hardly been studied. Large scale WP penetration in the economic emission dispatch problem was investigated in [33] where the intermittent WP output was described by a chance constraint. An enhanced security-constrained unit commitment model for wind power generation with the integration of compressed air energy storage was developed and formulated in [34]; furthermore, they investigated its impacts on the power system operational parameters. In [35], a conventional feedback-based control scheme with revisions for optimal use of the BESS that is integrated with a large wind farm was proposed with the purpose of enabling wind farm dispatching on an hourly basis. The offered control scheme was capable of incorporating several operating constraints of BESSs, such as charge/discharge rate, state of charge limits, and lifetime.

Alham et al. [36] proposed a formulation for the wind-thermal dynamic dispatch problem, incorporating ESS and demand-side management, when the probability of uncertain WP was considered as a chance constraint to avoid the use of the average of WP. Furthermore, the problem was solved using the general algebraic modeling system (GAMS).

\subsection{Contributions of the Work}

In this regard, this paper proposes a modified formulation for the wind-battery-thermal UCP (WBTUCP) that merges an energy storage system with a traditional power network to fulfill the power dispatch gap caused by uncertain wind power generation. The model is designed to enhance the dispatchability and flexibility of wind power to procure an optimal and minimum power generation cost, whilst taking into consideration the boundaries of the generation units and the restrictions of a power network. Unlike most of the studies in the literature, this study reveals the relationship between high demand, stochastic wind power, charging/discharging of BESSs, and the dispatchability of the generating units. The rated power and the charging/discharging time of the BESS are involved in the formulation problem to effectively participate in the scheduling of the generating units. In addition, the model examines the performance of the BESS to fulfill the gap in power production that is mainly caused by the unavailability of wind power during a high deviation in demand.

The Mixed-Integer Linear Programming (MILP) method was chosen to effectively implement the optimization problem due to its high efficiency and flexibility of defining variables and constraints. The MILP efficiently allowed variable probabilities of WP to be considered in the optimization problem without affecting the smoothness or the speed of the master problem. One of the important features of the MILP is its ability to generate sub-problems that are connected to the objective function, or what is 
called the "master problem". The uncertainty of WP is classified as a "sub-problem" and is separately computed from the master problem of the MILP. The master problem tracks and minimizes the overall operation cost of the entire model. In order to ensure an accurate power generation dispatch, the WBTUCP formulation gathers all system operating constraints. The uncertainty of WP is described in the suggested model by a chance constraint to avoid the high probabilistic infeasibility generated by classical models. This constraint defines the probability that the energy balance constraint cannot be met.

For computational purposes, the chance constraint is converted into a deterministic constraint by using a probability distribution function and a cumulative distribution function.

Three case studies were investigated to examine the proposed model. The obtained results confirm the great added value of utilizing WP and ESS for reducing energy production costs.

The rest of this paper is organized as follows: Section 2 describes the research methodology adopted in this study. Simulation results are shown in Section 3. Finally, the study's conclusions and future work are presented in Section 4.

\section{Materials and Methods}

\subsection{Characterization of Wind Power Uncertainty}

In this study, the WBTUCP was formulated as a chance-constrained problem (CCP). The chance-constrained optimization strategies have been applied in many research areas, for instance, UC problems [37], reserve scheduling [38], power dispatch problems [33], and finance and management [39]. Although several attempts have been proposed in the literature to model the CCPs, solving such problems remains a difficult task in terms of computation. Generally, a CCP with an uncertain constraint can be described as follows [33]:

$$
\left\{\begin{array}{l}
\min f(x), \quad x \in X \\
\text { subject to } \operatorname{Pr}\{h(x, \xi) \leq 0\} \geq 1-\sigma
\end{array}\right.
$$

where $X \subset \mathfrak{R}^{N}$ is the deterministic feasible region. $x \in \mathfrak{R}^{N}$ and $\xi \in \mathfrak{R}^{D}$ are the vectors of decision and uncertain variables. $\sigma \in[0,1]$ is the tolerance that constraint $h(x, \xi) \leq 0$ cannot be met. In the stochastic optimization literature, $(1-\sigma)$ is known as the value-at-risk. $f: \quad \mathfrak{R}^{N} \rightarrow \mathfrak{R}$ and $h: \quad \mathfrak{R}^{N} \times \mathfrak{R}^{D} \rightarrow \mathfrak{R}$ are assumed to be continuously differentiable in variable $x$. Finally, $\operatorname{Pr}(\bullet)$ is the probability of event $(\bullet)$. In many CCPs, the uncertain constraint given in Equation (1) is replaced by $\operatorname{Pr}\{h(x, \xi) \geq 0\} \geq 1-\sigma$.

Various techniques for solving the CCP have been proposed in the literature [40,41]. In the power system field, mostly, the problem has been converted into a deterministic problem [41].

In this study, the Weibull probability distribution function with two parameters developed in (2) is used to describe the volatility of wind speed. From Equation (2), the cumulative distribution function can be expressed as in (3). Moreover, the speed-power relationship of the wind farm is described by Equations (4)-(6).

$$
\begin{gathered}
f_{V}(v)=\frac{k}{c}\left(\frac{v}{c}\right)^{k-1} \exp \left[-\left(\frac{v}{c}\right)^{k}\right] \\
F_{V}(v)=\int_{0}^{v} f_{V}(\tau) d \tau=1-\exp \left(-\left(\frac{v}{c}\right)^{k}\right), v \geq 0 \\
W=\phi(V)=0, \text { if } V<v_{\text {in }} \text { or } V>v_{\text {out }} \\
W=\phi(V)=\frac{\left(V-v_{\text {in }}\right) w_{r}}{v_{r}-v_{\text {in }}} \text { if } v_{\text {in }} \leq V<v_{r} \\
W=\phi(V)=w_{r}, \text { if } v_{r} \leq V<v_{\text {out }}
\end{gathered}
$$


From Equations (4)-(6), the characteristics of WP output can be evaluated by using the combined continuous-discrete cumulative distribution function, expressed as follows:

$$
F_{W}(w)=\operatorname{Pr}(W \leq w)=\left\{\begin{array}{cc}
0, & (w<0) \\
1-\exp \left\{-\left(\frac{\left(1+\frac{h w}{w_{r}}\right) v_{\text {in }}}{c}\right)^{k}\right\}+\exp \left(-\left(\frac{v_{\text {out }}}{c}\right)^{k}\right), & 0 \leq w<w_{r} \\
1, & \left(w \geq w_{r}\right)
\end{array}\right.
$$

where $h=\frac{v_{r}-v_{\text {in }}}{v_{\text {in }}}$.

\subsection{Problem Formulation}

The WBTUCP problem is stated as determining the optimum scheduling of the generation between thermal power plants, wind turbines, and ESSs, such that the total production cost is minimized over a time horizon. Mostly, the WBTUCP is solved while satisfying a set of technical and security constraints. The decision variables of the problem are the status and the generation of each power energy source.

\subsubsection{Objective Function}

In general, the total production cost can be described as follows [11]:

$$
C_{T}=\left[\sum_{t=1}^{T} \sum_{i=1}^{N} C_{i}\left(P_{i}^{t}\right)\right] u_{i}^{t}+\left[\sum_{t=1}^{T} \sum_{i=1}^{N} S_{i}^{t}\right] u_{i}^{t}\left(1-u_{i}^{t-1}\right)+\left[\sum_{t=1}^{T} \sum_{i=1}^{N} D_{i}^{t}\right] u_{i}^{t-1}\left(1-u_{i}^{t}\right)
$$

In Equation (1), the first component corresponds to the total fuel cost. The fuel cost of the $i$-th unit at time $t$ is a nonlinear function that depends on the real output power. In this study, this function is described by piecewise linear functions that include the no-load cost $\left(C_{i}^{n l}\right)$ and the segment fuel $\operatorname{costs}\left(F C_{i, s}\right)$. For more accuracy of the linear model, enough segments are used. This can be shown in Equation (9).

$$
C_{i}\left(P_{i}^{t}\right)=C_{i}^{n l}+\sum_{s \in S} F C_{i, s} P_{i, s}^{t}
$$

The second component of Equation (8) represents the start-up cost, which is the required cost for restarting the unit from the OFF status to the ON status. It comprises mainly the reheating and maintenance costs. As given in Equation (10), the start-up cost can be described by the two-valued staircase expression:

$$
S_{i}^{t}=\left\{\begin{array}{lll}
S_{h i} & \text { if } & T_{i, \text { OFF }}^{t} \leq T_{i}^{D}+T_{i}^{C} \\
S_{c i} & \text { if } & T_{i, \text { OFF }}^{t}>T_{i}^{D}+T_{i}^{C}
\end{array}\right.
$$

Concerning the third component of Equation (8), it represents the shut-down cost, corresponding to the transition cost of units from the online status to the offline status. This cost is frequently neglected for UCPs.

\subsubsection{Problem Constraints}

The objective function is a minimized subject to the following constraints:

\section{Security Constraints}

The power flow in the line $l$ at time $t$ is constrained by its thermal limits as follows:

$$
\left|P F_{l}^{t}\right| \leq P F_{l}^{\max }
$$


Dispatchable Unit Constraints

The generation limits of all committed units are described by the following equation:

$$
P_{i}^{\min } \leq P_{i}^{t} \leq P_{i}^{\max }, \quad i=1,2, \ldots, N
$$

Minimum Up/Down Times

These constraints indicate the minimum required times for which the committed/de-committed unit can be turned OFF/ON. They can be expressed by Equation (13).

$$
\left\{\begin{array}{l}
T_{i, \text { ON }}^{t}>T_{i}^{U} \\
T_{i, \text { OFF }}^{t}>T_{i}^{D}
\end{array}\right.
$$

Spinning Reserve Constraints

In order to meet the system load requirement, a certain quantity of extra spinning generating capacity has to be reserved. The constraint on the spinning reserve is described as the following:

$$
\sum_{i=1}^{N} P_{i}^{t} u_{i}^{t}+P_{w}^{t}+P_{E S S}^{t} \geq P_{D}^{t}+S R^{t}
$$

Power Balance Constraint

The total generation of power from thermal units, wind energy sources, and storage system has to meet the total load plus system losses at any given time $t$. This condition is described by the following power balance constraint:

$$
\sum_{i=1}^{N}\left(P_{i}^{t}\right) u_{i}^{t}+P_{w}^{t}+P_{E S S}^{t}-P_{D}^{t}-P_{L}^{t}=0
$$

The total losses can be calculated using the B-loss formula, given as follows [33]:

$$
P_{L}=\sum_{i=1}^{N} \sum_{j=1}^{N}\left(P_{i}^{t}\right) u_{i}^{t} B_{i j}\left(P_{j}^{t}\right) u_{j}^{t}+\sum_{i=1}^{N} B_{o i}\left(P_{i}^{t}\right) u_{i}^{t}+B_{o o}
$$

High penetration of WP can help in decreasing total production costs and emissions. Unfortunately, the intermittent nature of wind energy raises some challenges, especially for large utilization of this type of energy. Therefore, it is important to study and develop methods to overcome these challenges. In this paper, the inclusion of WP in the UCP is modeled by modifying the power balance constraint in order to consider the random characteristics of wind energy source output. Therefore, the power balance constraint described by Equation (15) is converted into chance constraint as given in the following equation:

$$
\operatorname{Pr}\left(\sum_{i=1}^{N}\left(P_{i}^{t}\right) u_{i}^{t}+P_{w}^{t}+P_{E S S}^{t} \leq P_{D}^{t}+P_{L}^{t}\right) \leq \sigma
$$

In Equation (17), $\sigma$ is the tolerance that power balance cannot be met. It means that the more $\sigma$ increases, the more usage of WP increases and vice versa.

Equation (17) can be rewritten as the following:

$$
\operatorname{Pr}\left(\sum_{i=1}^{N}\left(P_{i}^{t}\right) u_{i}^{t}+P_{w}^{t}+P_{E S S}^{t}-P_{D}^{t}-P_{L}^{t}\right) \geq 1-\sigma
$$


Using the continuous characteristic in Equation (7) for WP output between 0 and $w_{r}$, the stochastic power balance constraint described by Equation (17) can be described by the following deterministic constraint:

$$
\operatorname{Pr}\left\{W \leq P_{D}+P_{L}-\sum_{i=1}^{N}\left(P_{i}^{t}\right) u_{i}^{t}-P_{w}^{t}-P_{s}^{t}\right\}=F_{W}\left(P_{D}+P_{L}-\sum_{i=1}^{N}\left(P_{i}^{t}\right) u_{i}^{t}-P_{w}^{t}-P_{s}^{t}\right) \leq \sigma
$$

For practical applications, the tolerance $\sigma$ should be written as the following:

$$
\operatorname{Pr}(W=0) \leq \sigma<1
$$

\section{BESS Constraints}

Due to the intermittent characteristics of WP, ESSs, such as BESSs, are mostly used to meet the load requirements. The operation cost of BESS is constrained by the following inequality [3]:

$$
\left(P_{E S S}^{r d} \times C P_{E S S}\right)+\left(E_{E S S}^{r d} \times C E_{E S S}\right) \leq C A P_{E S S}
$$

As given in Equation (22), the rated energy of the BESS is the rated power of the BESS times the charging/discharging time. The charging/discharging power can be calculated as given in Equation (23).

$$
\begin{gathered}
E_{E S S}^{r d}=P_{E S S}^{r d} \times T_{E S S}^{c h / d i s} \\
P_{E S S}^{t}=P_{d i s}^{t} \times d i s_{E S S}^{t}+P_{c h}^{t} \times c h_{E S S}^{t}
\end{gathered}
$$

The charging and discharging powers are limited by their maximum limits, as shown in Equations (24) and (25), respectively. In this study, the charging power is negative while the discharging power is positive.

$$
\begin{gathered}
-P_{c h}^{t} \leq P_{c h}^{\max } c h_{E S S}^{t} \\
P_{d i s}^{t} \leq P_{d i s}^{\max } \times \eta_{E S S} \times d i s_{E S S}^{t}
\end{gathered}
$$

It is worth noting that the BESS cannot charge and discharge at the same time. Thus, it can be written as the following:

$$
c h_{E S S}^{t} \times d i s_{E S S}^{t}=0
$$

The stored energy at time $t$ is constrained by Equation (27) and it can be calculated using Equation (28).

$$
\begin{gathered}
0 \leq E_{E S S}^{t} \leq E_{E S S}^{r d} \\
E_{E S S}^{t}=E_{E S S}^{t-1}-P_{E S S}^{t} \times c h_{E S S}^{t}+P_{E S S}^{t} \times d i s_{E S S}^{t} \times \eta_{E S S}
\end{gathered}
$$

\subsection{Implementation of the Proposed Method}

The flowchart of the optimization problem, suggested for the WBTUCP, is depicted in Figure 1. First, all the input data, including generating units, hourly demand, rated power of the BESS, and the transmission lines boundaries are gathered in the first stage. Then, the optimization problem clears the uncertainty of WP through the chance-constrained programming. The master problem seeks the feasibility of the MILP for the minimum operation cost; then, the network evaluation is tested in sub-problems. Once the optimization problem ensures that there is no violation of the network constraints, a final and optimal solution will be generated. If any variable violates at least one network constraint, a cut will be generated to return back for further possible variables. 


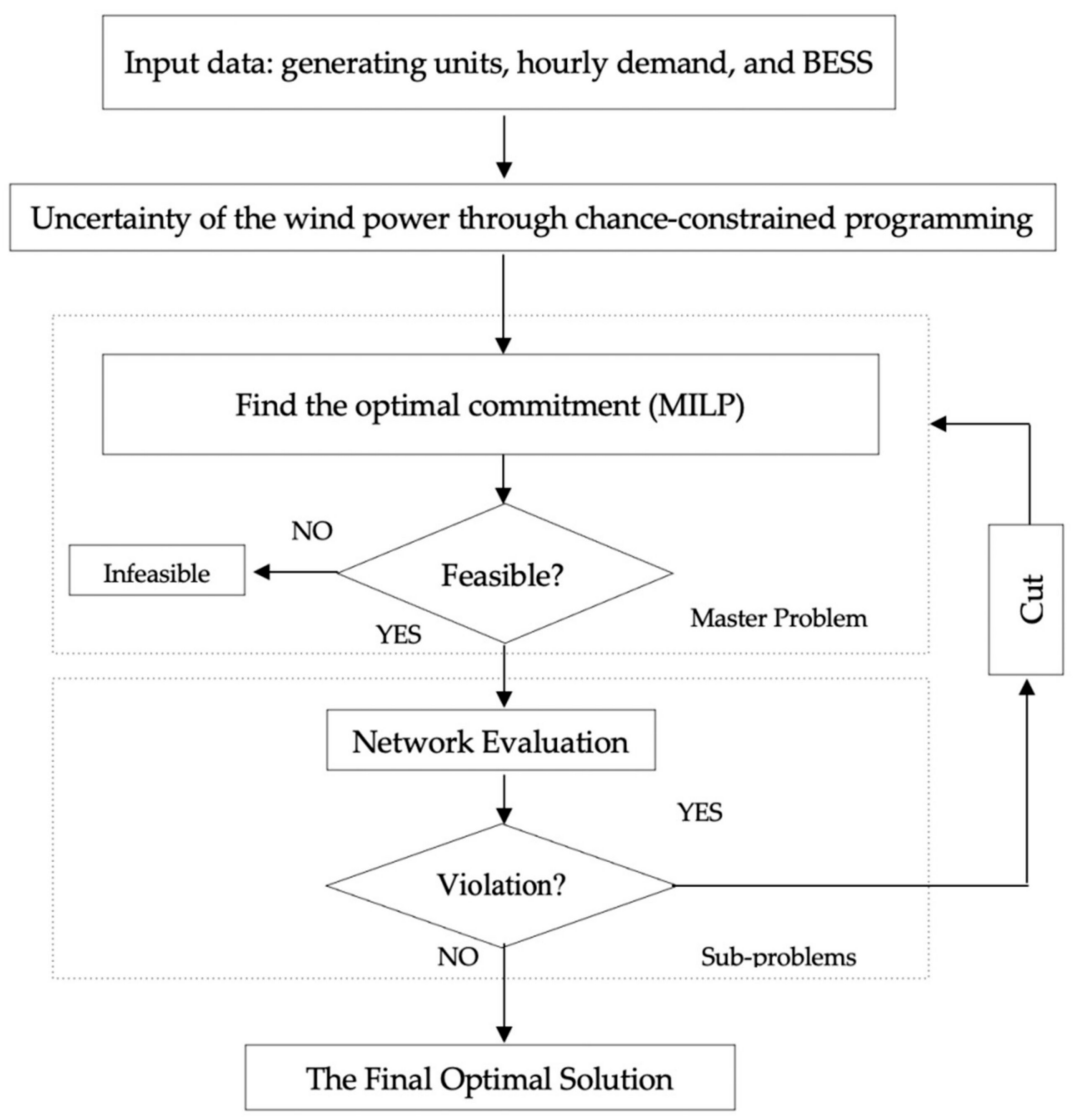

Figure 1. Flowchart of the overall proposed optimization method.

\section{Results and Discussion}

The ten-generating unit system [33] was used to perform the optimization technique proposed previously. The system includes ten dispatchable units based on fossil fuel, one wind power unit, 17 loads, and one energy storage unit. The specification of the generating units and their limitations were taken from [42] and shown in Table 1. The solution to the optimization problem was procured on a personal computer using GAMS software. GMAS software is originally developed by a group of economists from the World Bank in Washington, United States. The software was installed on a personal computer with $8 \mathrm{GHz}$ RAM and an Intel Core i7 $1.8 \mathrm{GHz}$.

Table 1. Unit characteristics.

\begin{tabular}{cccccccccccc}
\hline Unit & $\boldsymbol{P}_{i}^{\min }$ & $\boldsymbol{P}_{\boldsymbol{i}}^{\max }$ & $\boldsymbol{a}_{\boldsymbol{i}}$ & $\boldsymbol{b}_{\boldsymbol{i}}$ & $\boldsymbol{c}_{\boldsymbol{i}}$ & $\boldsymbol{T}_{\boldsymbol{i}}^{\boldsymbol{U}}(\boldsymbol{h})$ & $\boldsymbol{T}_{\boldsymbol{i}}^{D}(\boldsymbol{h})$ & $\boldsymbol{S}_{\boldsymbol{h i}}(\mathbf{\$})$ & $\boldsymbol{S}_{\boldsymbol{c} i}(\$)$ & $\boldsymbol{T}_{\boldsymbol{i}}^{\boldsymbol{C}}(\boldsymbol{h})$ & $\boldsymbol{I} \boldsymbol{S}_{\boldsymbol{i}}(\boldsymbol{h})$ \\
\hline 1 & 150 & 455 & 1000 & 16.19 & 0.00048 & 8 & 8 & 4500 & 9000 & 5 & 8 \\
\hline 2 & 150 & 455 & 917 & 17.26 & 0.00031 & 8 & 8 & 5000 & 10,000 & 5 & 8 \\
\hline 3 & 20 & 130 & 700 & 16.60 & 0.00200 & 5 & 5 & 550 & 1100 & 4 & -5 \\
\hline 4 & 20 & 130 & 680 & 16.50 & 0.00211 & 5 & 5 & 560 & 1120 & 4 & -5 \\
\hline 5 & 25 & 162 & 450 & 19.70 & 0.00398 & 6 & 6 & 900 & 1800 & 4 & -6 \\
\hline 6 & 20 & 80 & 370 & 22.26 & 0.00712 & 3 & 3 & 170 & 340 & 2 & -3 \\
\hline 7 & 25 & 85 & 480 & 27.74 & 0.00079 & 3 & 3 & 260 & 520 & 2 & -3 \\
\hline 8 & 10 & 55 & 660 & 25.92 & 0.00413 & 1 & 1 & 30 & 60 & 0 & -1 \\
\hline 9 & 10 & 55 & 665 & 27.27 & 0.00222 & 1 & 1 & 30 & 60 & 0 & -1 \\
\hline 10 & 10 & 55 & 770 & 27.79 & 0.00173 & 1 & 1 & 30 & 60 & 0 & -1 \\
\hline
\end{tabular}


The optimization problem contains many sets, parameters, and variables, as well as multiple constraints and boundaries. The quadratic cost functions of each generating unit, including the hourly generation, start-up, and shut-down costs, were precisely converted into a high number of linear segments. This step was important to define the objective function and all the related system constraints as MILP. The MILP algorithm was applied to achieve the optimal dispatch of the generating units with the minimum possible operating costs. Three case studies were investigated to examine the proposed model.

\subsection{Case 1: Operating Cost with Various Demand}

The objective function was to minimize the operation cost of the ten-generating units with variable demand. The hourly variation of the load is shown in Table 2 . The aim of this case was to investigate how the generating units would react when the demand increases. It is worth noting that the generation outputs of units provided in Table 1 were totally dependent on the uncertainties of the hourly rated wind power illustrated in Table 2. For instance, Unit 8, with flexible minimum up/down time would increase or decrease the output power according to its maximum capacity, as well as the availability of WP at hour $h$. Therefore, any future change on the given data of the generation units and the uncertainty of WP might significantly increase or decrease the hourly operation cost.

Table 2. Hourly load and rated WP.

\begin{tabular}{lcccccccc}
\hline Hour & 1 & 2 & 3 & 4 & 5 & 6 & 7 & 8 \\
\hline Wind & 44 & 70.2 & 76 & 82 & 84 & 84 & 100 & 100 \\
\hline Demand & 170 & 175.19 & 165.15 & 158.67 & 154.73 & 155.06 & 160.48 & 173.39 \\
\hline Hour & 9 & 10 & 11 & 12 & 13 & 14 & 15 & 16 \\
\hline Wind & 78 & 64 & 100 & 92 & 84 & 80 & 78 & 32 \\
\hline Demand & 177.6 & 186.81 & 206.96 & 228.61 & 236.1 & 242.18 & 243.6 & 248.86 \\
\hline Hour & 17 & 18 & 19 & 20 & 21 & 22 & 23 & 24 \\
\hline Wind & 4 & 0 & 10 & 0 & 6 & 56 & 82 & 52 \\
\hline Demand & 255.79 & 256 & 246.74 & 245.97 & 237.35 & 237.31 & 232.67 & 195.93 \\
\hline
\end{tabular}

The power supply of all generating units with variation in demand is depicted in Figure 2. The hourly demand increased from 0 to $15 \%$ of the base demand. Units $1-5$ were operating most of the time to cover the required demand of the power network since they have a lower production cost and a higher power supply capacity. In the base demand, Units 7 and 10 were completely shut down due to their limited power capacity and high production cost. The total operating hours of the power network dramatically increased from 109 to $132 \mathrm{~h}$, when hourly demand increased by $10 \%$. This increase in demand showed a $21 \%$ increase in the total operating hours, as compared with the base demand. However, any sudden increase in the hourly demand by $15 \%$ would lead to a failure in supplying the loads, which exceeds the maximum power supply of all generating units. The cumulative cost of operating the generating units in the base demand was $\$ 548,436$. The cumulative cost became $\$ 583,297$ and $\$ 618,760$ when the demand was increased to 5 and $10 \%$, respectively. The hourly cost of the generating units with various demands is depicted in Figure 3. 


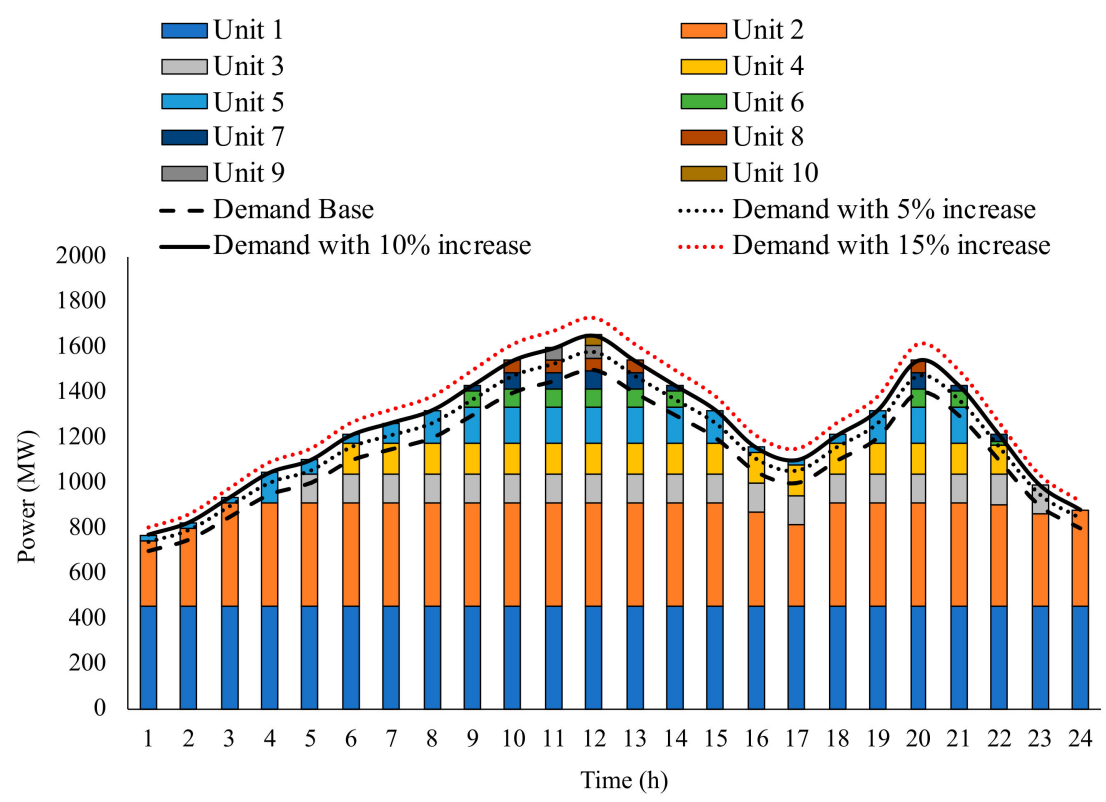

Figure 2. Hourly power dispatch of the generating units.

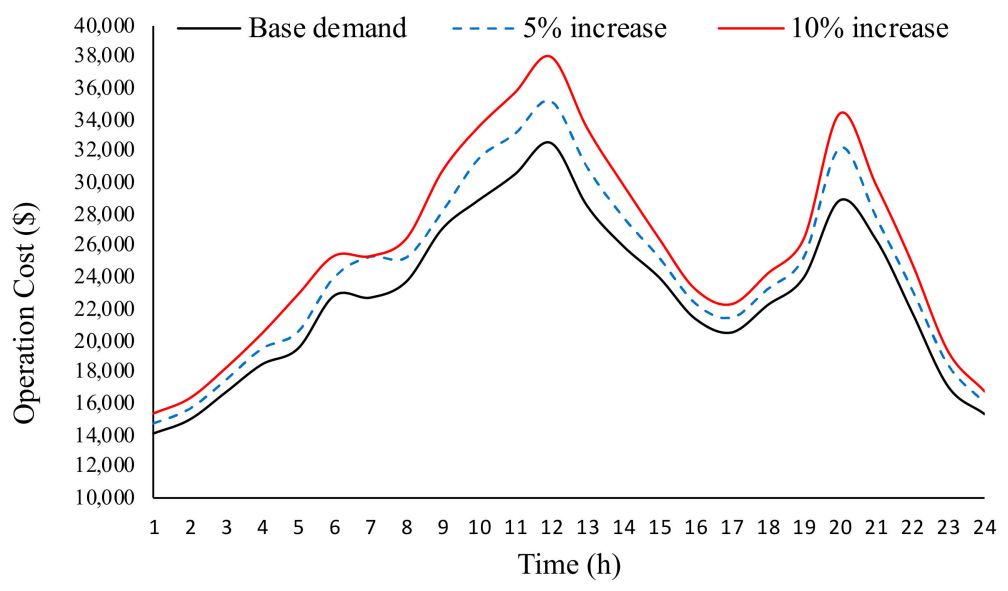

Figure 3. Hourly operation cost of the ten-unit system.

\subsection{Case 2: Incorporating Wind Power into Case 1}

Three WP units were then added to the power network to participate in supplying the load. The hourly variation of WP is shown in Table 2 . The hourly WP was obtained from (17), where the wind tolerance was considered to be 0.25 . When WP was injected into the power network, the power supply schedule changed. In this case, the participation of WP had an efficient reduction in the total generation, as compared with Case 1. The inclusion of WP successfully reduced the total generation by 953.5 MWh (megawatt-hours) over a 24-h period of time. The reduction of the total generation was $3.52,3.37$, and $3.19 \%$ when the demand increased by 0,5 , and $10 \%$, respectively. Figure 4 demonstrates the power supply of the wind source and the dispatchable units, with an increase in demand of $10 \%$. The total generation cost in this case, with base demand, became $\$ 527,070$, which was $\$ 548,436$ in Case 1. The hourly operation cost comparison between Cases 1 and 2 is presented in Table 3. Although WP reduced the generation cost, the supply from the wind and the dispatchable units failed to satisfy the loads when the demand increased to $15 \%$. The reason behind this is due to the unavailability of WP, especially at certain hours, such as hour 18 and 20. The intermittent WP did not provide a sufficient response to the sudden increase in demand, which requires an alternative solution for economic and security purposes. 


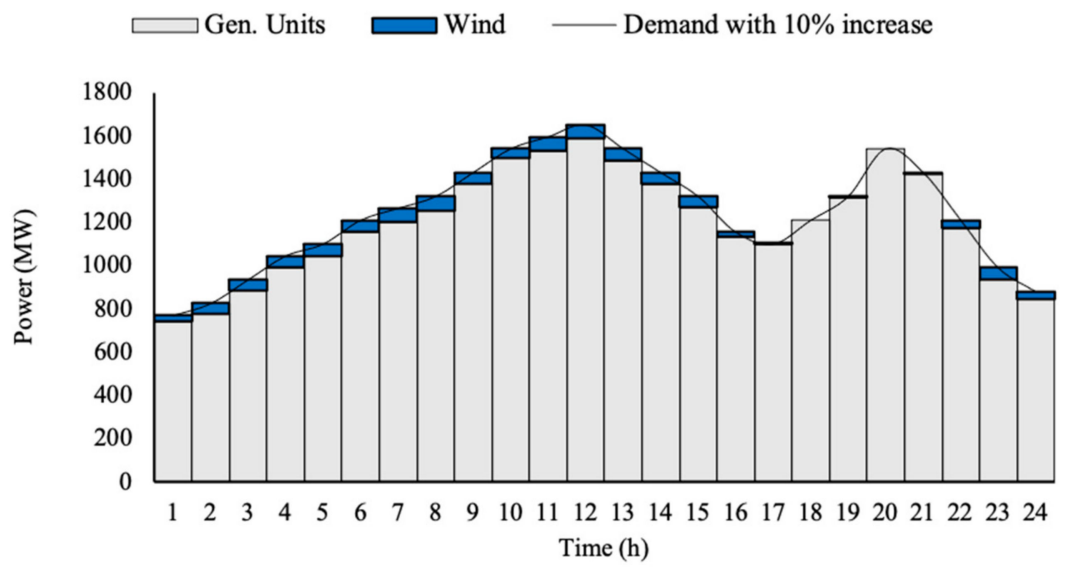

Figure 4. Hourly total power supply in Case 2 with a 10\% increase in demand.

Table 3. Generation cost comparison between Case 1 and Case 2 with various demand (\$).

\begin{tabular}{|c|c|c|c|c|c|c|}
\hline \multirow[b]{2}{*}{ Time (h) } & \multicolumn{2}{|c|}{ Base Demand } & \multicolumn{2}{|c|}{$5 \%$ Increase in Demand } & \multicolumn{2}{|c|}{$10 \%$ Increase in Demand } \\
\hline & Case 1 & Case 2 & Case 1 & Case 2 & Case 1 & Case 2 \\
\hline 1 & $14,096.871$ & $13,085.2771$ & $14,703.9326$ & $14,204.4081$ & $15,311.473$ & $14,811.4691$ \\
\hline 2 & $14,964.101$ & $13,655.9145$ & $15,615.497$ & $14,818.407$ & $16,266.977$ & $15,469.5655$ \\
\hline 3 & $16,701.467$ & $15,326.8513$ & $17,441.0136$ & $16,576.5603$ & $18,180.5603$ & $17,316.0737$ \\
\hline 4 & $18,478.989$ & $16,998.0463$ & $19,430.1115$ & $18,357.0665$ & $20,390.1267$ & $19,307.3372$ \\
\hline 5 & $19,480.346$ & $20,180.613$ & $20,491.8107$ & $19,381.2831$ & $22,856.3637$ & $20,391.5503$ \\
\hline 6 & $22,844.478$ & $20,391.5503$ & $23,951.4571$ & $22,845.8759$ & $25,323.6651$ & $23,952.8729$ \\
\hline 7 & $22,730.329$ & $22,537.7754$ & $25,253.7783$ & $22,571.1562$ & $25,305.4919$ & $23,737.4175$ \\
\hline 8 & $23,744.941$ & $22,419.7771$ & $25,205.0219$ & $23,635.7335$ & $26,419.8541$ & $26,197.1171$ \\
\hline 9 & $27,113.117$ & $26,083.9879$ & $28,114.2847$ & $27,397.8333$ & $30,716.1723$ & $28,430.7099$ \\
\hline 10 & $28,908.081$ & $27,960.1293$ & $31,452.7026$ & $30,673.9375$ & $33,502.7721$ & $32,859.8424$ \\
\hline 11 & $30,550.903$ & $28,218.4854$ & $33,016.3149$ & $30,575.0763$ & $35,671.6514$ & $33,154.4839$ \\
\hline 12 & $32,561.655$ & $30,286.2052$ & $35,115.7099$ & $32,803.7353$ & $37,972.325$ & $35,528.4463$ \\
\hline 13 & $28,568.081$ & $27,340.8953$ & $30,932.7026$ & $29,451.5533$ & $33,442.7721$ & $31,351.6221$ \\
\hline 14 & $26,013.117$ & $25,183.2736$ & $27,774.2847$ & $26,271.5988$ & $29,856.1723$ & $28,061.5536$ \\
\hline 15 & $24,004.372$ & $22,710.1047$ & $25,205.0219$ & $24,183.7104$ & $26,419.8541$ & $25,386.1307$ \\
\hline 16 & $21,383.604$ & $20,401.5602$ & $22,295.6764$ & $21,931.89$ & 23,209.1917 & $22,844.8127$ \\
\hline 17 & $20,515.33$ & $19,849.4233$ & $21,383.6044$ & $21,337.219$ & $22,252.2444$ & $22,205.859$ \\
\hline 18 & $22,252.244$ & $21,724.4791$ & 23,209.1917 & 23,209.1917 & $24,203.6651$ & $24,203.6651$ \\
\hline 19 & $24,004.372$ & $24,977.916$ & $25,205.0219$ & $25,073.0043$ & $26,419.8541$ & $26,286.2413$ \\
\hline 20 & $28,908.081$ & $28,908.0813$ & $32,150.0466$ & $32,150.0466$ & $34,362.7721$ & $34,894.708$ \\
\hline 21 & $26,426.543$ & $26,346.4511$ & $27,774.2847$ & $27,685.119$ & $29,856.1723$ & $29,866.729$ \\
\hline 22 & $21,803.274$ & $21,006.8728$ & $23,168.4458$ & 22,222.1993 & $24,864.4218$ & $23,488.104$ \\
\hline 23 & $17,060.864$ & $16,747.3596$ & $18,390.4679$ & $16,911.0408$ & $19,243.1003$ & $18,196.5059$ \\
\hline 24 & $15,321.292$ & $14,730.2693$ & $16,016.7983$ & $15,425.1813$ & $16,712.8423$ & $16,120.8569$ \\
\hline
\end{tabular}

From the results of this case, it is clear that the impacts of stochastic WP on the total generation of thermal units can be readily assessed when the power balance constraint is described by a chance constraint. In addition, the description of the uncertainty of WP by probability distribution can be 
used as a solution to avoid the high probabilistic infeasibility coming from average WP in a range of 0.75 , as calculated in [41]. However, the tolerance that power balance constraint cannot be met should be high enough in such a way that the wind farm can react to the sudden increase in power demand.

\subsection{Case 3: Adding Energy Storage to Case 2}

Based on the results presented in the previous section, wind energy sources cannot reach more than a $15 \%$ increase in demand power since the tolerance describing the uncertainty of WP is 0.25 . Therefore, increasing the tolerance of $P_{a}$ is a must to make the increase of the penetration of WP possible. Unfortunately, increasing the tolerance leads to neglecting the impact of the variability and uncertainty of WP. In addition, if the tolerance reaches high values, the decision-makers will take more risks associated with WP penetration.

In this case, a battery storage unit was added to the power network to regulate the output of the wind energy source. The characteristics of a lithium-ion battery were applied in this study to track the intermittency of the wind power, due to its high efficiency and the fast charging/discharging time. The discharging time for a lithium-ion is precisely one hour, to cover the unavailability of the wind power during a short time. The minimum rated power and energy of the battery storage to satisfy the demand was found to be $10 \mathrm{MW}$ and $10 \mathrm{MWh}$, respectively. The efficiency of the battery was considered to be $90 \%$. The optimization problem will seek the ability to charge the battery at a low production cost and reuse it when needed. The battery storage gave an opportunity to store the excess energy from the wind energy source when demand was at off-peak times. The operation of the charging/discharging of the battery storage is illustrated in Figure 5. The power supply in this case successfully fulfilled all the energy balance constraints even though the demand increased by $15 \%$. The power supply schedule in this case, with the variable demand, is given in Table 4 . For example, the battery discharged the full capacity at hour 20 since the WP was totally absent unprecedented. The hourly operation cost comparison between all cases is depicted in Figure 6. Although the reduction of the hourly operation cost was low when using the battery storage, the power dispatch was significantly enhanced to meet the required demand. Moreover, a summary of the total operation cost in all cases with the variable demand is illustrated in Figure 7. In contrast to Case 2, when BESS and WP were incorporated simultaneously into the problem, the chance constraint Equation (18) was fulfilled when the demand increased by $15 \%$. Thus, the inclusion of BESS can help in mitigating the risk of insufficient WP for a significant increase in demand power.

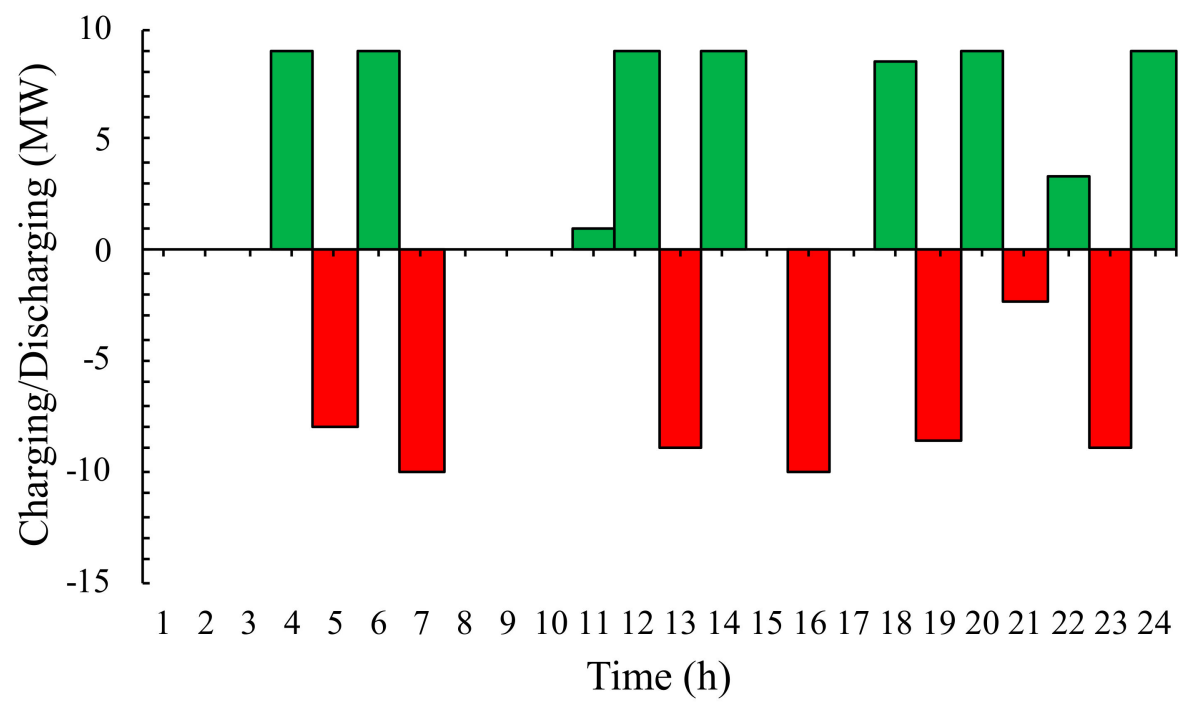

Figure 5. The charging/discharging of the battery storage. 
Table 4. Power supply in Case 3 with various demands in Megawatts (MW).

\begin{tabular}{|c|c|c|c|c|c|c|c|c|}
\hline \multirow[b]{2}{*}{ Time (h) } & \multicolumn{4}{|c|}{ Base Demand } & \multicolumn{4}{|c|}{$15 \%$ Increase in Demand } \\
\hline & $\begin{array}{l}\text { Generating } \\
\text { Units }\end{array}$ & Storage & Wind & Demand & $\begin{array}{l}\text { Generating } \\
\text { Units }\end{array}$ & Storage & Wind & Demand \\
\hline 1 & 671.2 & & 28.8 & 700 & 776.2 & & 28.8 & 805 \\
\hline 2 & 704.1 & & 45.9 & 750 & 816.6 & & 45.9 & 862.5 \\
\hline 3 & 800.32 & & 49.68 & 850 & 927.82 & & 49.68 & 977.5 \\
\hline 4 & 887.39 & 9 & 53.61 & 950 & 1029.89 & 9 & 53.61 & 1092.5 \\
\hline 5 & 953.07 & -8 & 54.93 & 1000 & 1104.07 & -9 & 54.93 & 1150 \\
\hline 6 & 1036.07 & 9 & 54.93 & 1100 & 1201.07 & 9 & 54.93 & 1265 \\
\hline 7 & 1094.63 & -10 & 65.37 & 1150 & 1266.13 & -9 & 65.37 & 1322.5 \\
\hline 8 & 1134.63 & & 65.37 & 1200 & 1314.63 & & 65.37 & 1380 \\
\hline 9 & 1249 & & 51 & 1300 & 1444 & & 51 & 1495 \\
\hline 10 & 1358.15 & & 41.85 & 1400 & 1568.15 & & 41.85 & 1610 \\
\hline 11 & 1383.63 & 1 & 65.37 & 1450 & 1602.13 & & 65.37 & 1667.5 \\
\hline 12 & 1430.85 & 9 & 60.15 & 1500 & 1607 & 6.93 & 60.15 & 1674.08 \\
\hline 13 & 1354.07 & -9 & 54.93 & 1400 & 1552 & 3.07 & 54.93 & 1610 \\
\hline 14 & 1238.71 & 9 & 52.29 & 1300 & 1442.71 & & 52.29 & 1495 \\
\hline 15 & 1149 & & 51 & 1200 & 1329 & & 51 & 1380 \\
\hline 16 & 1039.06 & -10 & 20.94 & 1050 & 1186.56 & & 20.94 & 1207.5 \\
\hline 17 & 997.33 & & 2.67 & 1000 & 1157.33 & -10 & 2.67 & 1150 \\
\hline 18 & 1091.43 & 8.57 & 0 & 1100 & 1265 & & 0 & 1265 \\
\hline 19 & 1202 & -8.57 & 6.57 & 1200 & 1373.43 & & 6.57 & 1380 \\
\hline 20 & 1391 & 9 & 0 & 1400 & 1601 & 9 & 0 & 1610 \\
\hline 21 & 1298.41 & -2.37 & 3.96 & 1300 & 1490.04 & 1 & 3.96 & 1495 \\
\hline 22 & 1060 & 3.37 & 36.63 & 1100 & 1228.37 & & 36.63 & 1265 \\
\hline 23 & 855.39 & -9 & 53.61 & 900 & 990.39 & -9 & 53.61 & 1035 \\
\hline 24 & 756.98 & 9 & 34.02 & 800 & 876.98 & 9 & 34.02 & 920 \\
\hline
\end{tabular}

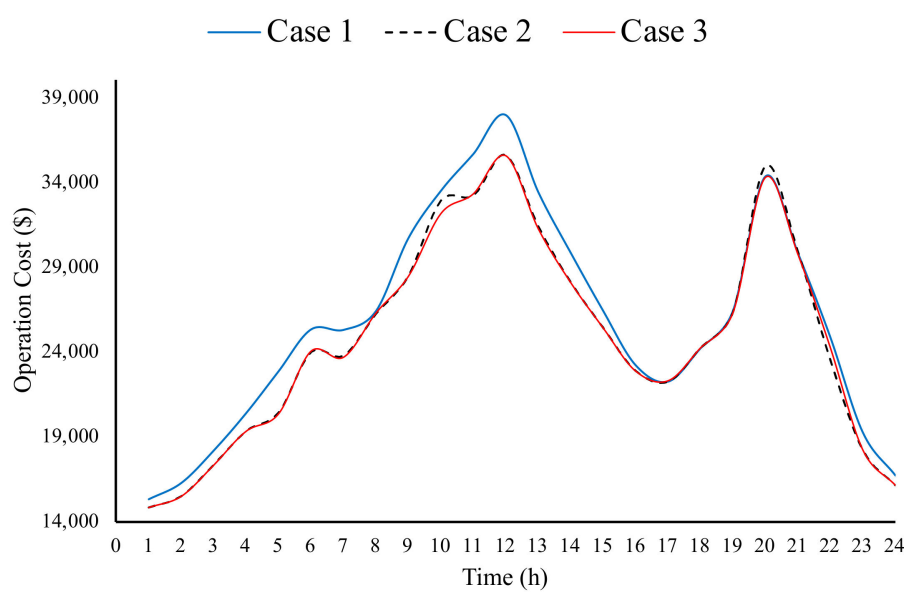

Figure 6. Comparison of the hourly operation cost between all cases. 


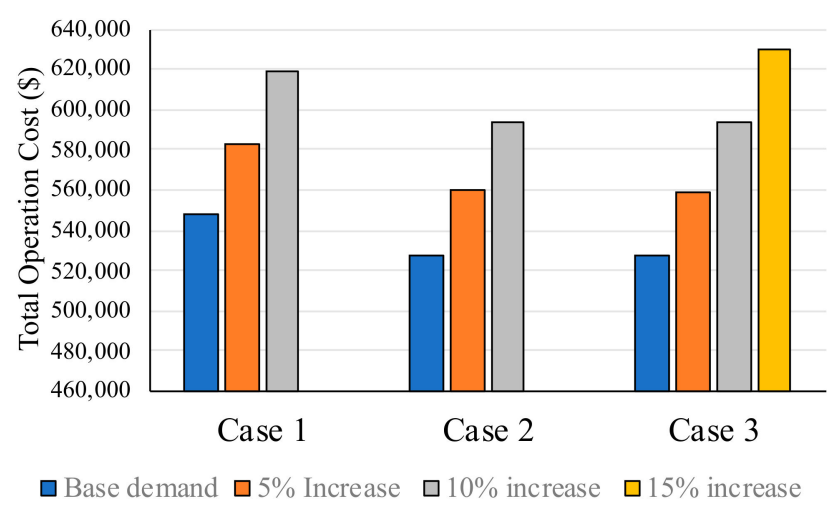

Figure 7. Total operation cost comparison of all cases with variable demand.

\section{Conclusions}

The deployment of the wind-battery-thermal UCP in modern power networks has been significantly increased to manage the raised concerns related to transmission congestions and high energy production costs. However, the merging of WP into the infrastructure of conventional power networks would challenge the system operators, especially during the volatility of the wind speed, which would eventually affect the regular scheduling of the dispatchable generation units. Therefore, this paper presented a modified optimization technique to fulfill the gap in the power supply during the availability of WP, whilst taking into consideration the operation cost of the power network. The study has suggested the utilization of a BESS to manage the risk caused by the intermittency of WP. The model has been designed to store the excess amount of energy directly from WP during off-peak times. A MILP-based model was used to efficiently incorporate WP and the BESS in scheduling the operating hours. The intermittency of WP was defined as a chance-constraint in the stochastic optimization problem. The performance of the suggested model was assessed through three case studies; (1) only thermal units, (2) including WP, and (3) including WP and BESS. The results illustrated that the participation of wind power could effectively decrease the daily power generation by $3.5 \%$. However, the inclusion of wind power generation was not enough to cover a sudden increase in the hourly demand by $15 \%$, which leads to the required installation of BESS. For future work, the model can be extended by including other renewable energy sources, such as a photovoltaic system, besides the operation of wind power and the BESS.

Author Contributions: K.A. has prepared the introduction and problem formulation parts and he has simulated results. T.G. has analyzed the results and supervised the work. A.F.A. and M.T.A. have prepared the rest of the paper sections. All authors have read and agreed to the published version of the manuscript.

Funding: This research received no external funding.

Conflicts of Interest: There is no conflict of interest.

\section{Nomenclature}

$\begin{array}{ll}N & \text { Number of units. } \\ T & \text { Scheduling period in hours. } \\ \mathrm{S} & \text { Set of segments. } \\ C_{T} & \text { Total production cost in } \$ . \\ a_{i}, b_{i} \text { and } c_{i} & \text { Cost coefficients } \\ P_{i}^{t} & \text { Generation in MW of unit i at time } t . \\ u_{i}^{t} & \text { Status of unit } i \text { at time } t . \\ S_{i}^{t} & \text { Start-up cost of unit } i \text { at time } t . \\ D_{i}^{t} & \text { Shut-down cost of unit } i \text { at time } t .\end{array}$




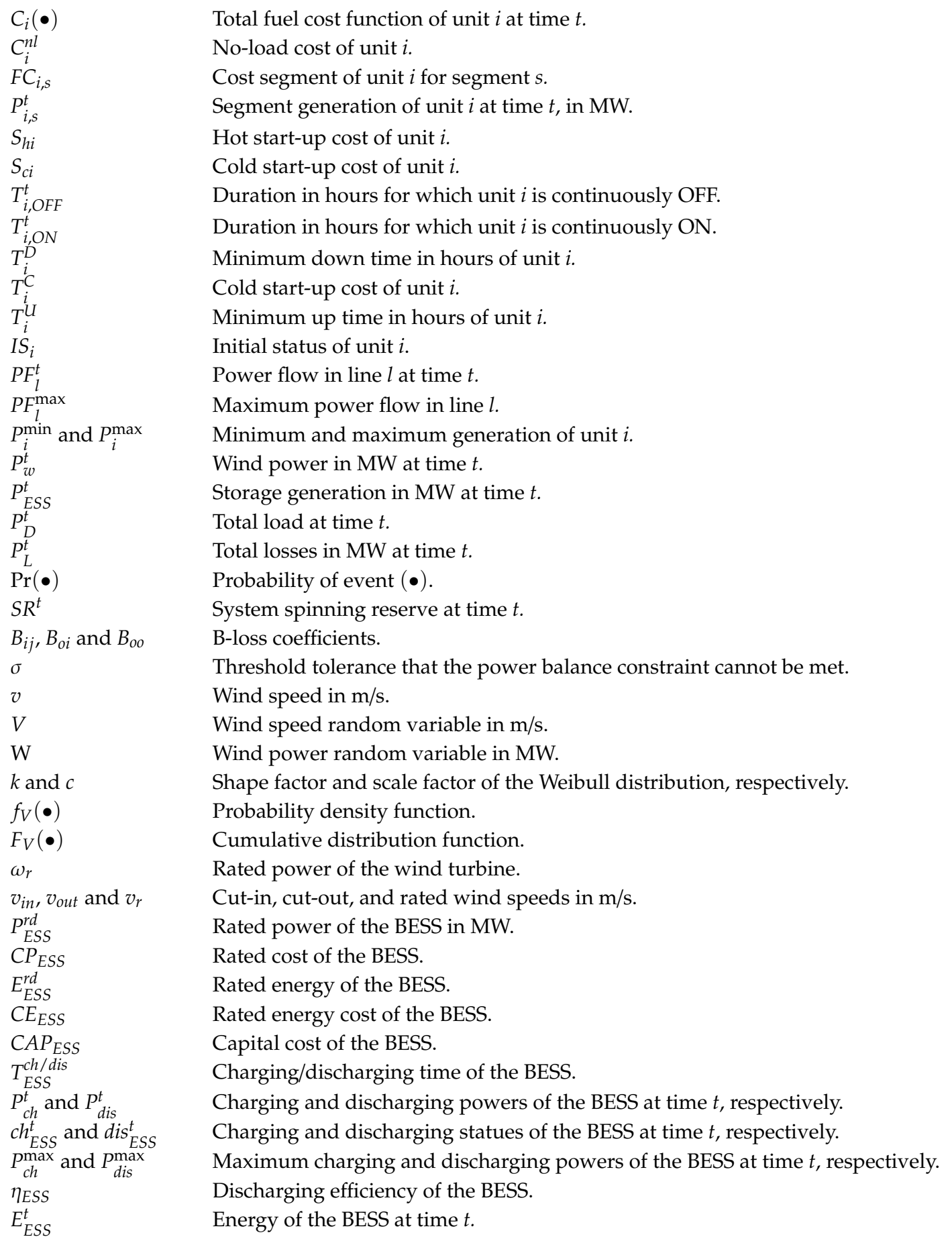

\section{References}

1. Hao, Y.; Liang, J.; Wang, K.; Wu, G.; Joseph, T.; Sun, R. Influence of active power output and control parameters of full-converter wind farms on sub-synchronous oscillation characteristics in weak grids. Energies 2020, 13, 5225. [CrossRef]

2. Zhao, H.; Wu, Q.; Hu, S.; Xu, H.; Rasmussen, C.N. Review of energy storage system for wind power integration support. Appl. Energy 2015, 137, 545-553. [CrossRef]

3. Ye, J.; Yuan, R. Integrated Natural Gas, Heat, and Power Dispatch Considering Wind Power and Power-to-Gas. Sustainability 2017, 9, 602. [CrossRef]

4. Elnaz, N.M.; Turaj, A.; Saberi, O.S. Stochastic very short-term economic dispatch for wind power operation using flexible ramp reserve. Int. Trans. Electr. Energy Syst. 2020, 30, e12454. 
5. Daneshi, H.; Srivastava, A.K. Security-constrained unit commitment with wind generation and compressed air energy storage. IET Gener. Transm. Distrib. 2012, 6, 167-175. [CrossRef]

6. Han, X.; Zhou, M.; Li, G.; Lee, K.Y. Stochastic unit commitment of wind-integrated power system considering air-conditioning loads for demand response. Appl. Sci. 2017, 7, 1154. [CrossRef]

7. Jain, A.; Huddar, A.P. Multi-objective-based robust unit commitment using hydro-thermal-wind: A hybrid technique. Int. J. Energy Sect. Manag. 2019, 13, 804-827. [CrossRef]

8. Nikolaidis, P.; Chatzis, S.; Poullikkas, A. Renewable energy integration through optimal unit commitment and electricity storage in weak power networks. Int. J. Sustain. Energy 2019, 38, 398-414. [CrossRef]

9. Sediqi, M.M.; Lotfy, M.E.; Ibrahimi, A.M.; Senjyu, T.; Narayanan, K. Stochastic unit commitment and optimal power trading incorporating PV uncertainty. Sustainability 2019, 11, 4504. [CrossRef]

10. Park, H.; Park, J.; Park, J.Y.; Heo, J.H. Considering maintenance cost in unit commitment problems. Energies 2017, 10, 1917. [CrossRef]

11. Morales-Espana, G.; Lorca, A.; de Weerdt, M.M. Robust unit commitment with dispatchable wind power. Electr. Power Syst. Res. 2018, 155, 58-66. [CrossRef]

12. Zhang, Y.; Lundblad, A.; Campana, P.E.; Yan, J. Comparative study of battery storage and hydrogen storage to increase photovoltaic self-sufficiency in a residential building of Sweden. Energy Procedia 2016, 103, 268-273. [CrossRef]

13. Basu, M. Economic environmental dispatch of solar-wind-hydro-thermal power system. Renew. Energy Focus 2019, 30, 107-122. [CrossRef]

14. Ortega, A.; Milano, F. Voltage stability of converter-interfaced energy storage systems. IFAC-PapersOnLine 2019, 52, 222-227. [CrossRef]

15. Paliwal, N.K.; Singh, A.K.; Singh, N.K.; Kumar, P. Optimal sizing and operation of battery storage for economic operation of hybrid power system using artificial bee colony algorithm. Int. Trans. Electr. Energy Syst. 2019, 29, 1-23. [CrossRef]

16. Liu, Y.; Wu, X.; Du, J.; Song, Z.; Wu, G. Optimal sizing of a wind-energy storage system considering battery life. Renew. Energy 2020, 147, 2470-2483. [CrossRef]

17. Sebastian, R. Battery energy storage for increasing stability and reliability of an isolated wind diesel power system. IET Renew. Power Gener. 2017, 11, 296-303. [CrossRef]

18. Liu, J.; Yao, W.; Fang, J.; Wen, J.; Cheng, S. Stability analysis and energy storage-based solution of wind farm during low voltage ride through. Int. J. Electr. Power 2018, 101, 75-84. [CrossRef]

19. Gurung, S.; Naetiladdanon, S.; Sangswang, A. Coordination of power-system stabilizers and battery energy-storage system controllers to improve probabilistic small-signal stability considering integration of renewable-energy resources. Appl. Sci. 2019, 9, 1109. [CrossRef]

20. Abbey, C.; Joos, G. Supercapacitor energy storage for wind energy applications. IEEE Trans. Ind. Appl. 2007, 43, 769-776. [CrossRef]

21. Zhang, S.; Mishra, Y.; Shahidehpour, M. Fuzzy-logic based frequency controller for wind farms augmented with energy storage systems. IEEE Trans. Power Syst. 2015, 31, 1595-1603. [CrossRef]

22. Barote, L.; Marinescu, C. Storage analysis for stand-alone wind energy applications. In Proceedings of the 12th International Conference on Optimization of Electrical and Electronic Equipment 2010, Basov, Romania, 20-22 May 2010; pp. 1180-1185.

23. Black, M.; Strbac, G. Value of bulk energy storage for managing wind power fluctuations. IEEE Trans. Energy Convers. 2007, 22, 197-205. [CrossRef]

24. Luo, F.; Meng, K.; Dong, Z.Y.; Zheng, Y.; Chen, Y.; Wong, K.P. Coordinated operational planning for wind farm with battery energy storage system. IEEE Trans. Sustain. Energy 2015, 6, 253-262. [CrossRef]

25. Arabali, A.; Ghofrani, M.; Etezadi-Amoli, M.; Fadali, M.S. Stochastic performance assessment and sizing for a hybrid power system of solar/wind/energy storage. IEEE Trans. Sustain. Energy 2013, 5, 363-371. [CrossRef]

26. Ghofrani, M.; Arabali, A.; Etezadi-Amoli, M.; Fadali, M.S. Energy storage application for performance enhancement of wind integration. IEEE Trans. Power Syst. 2013, 28, 4803-4811. [CrossRef]

27. Dicorato, M.; Forte, G.; Pisani, M.; Trovato, M. Planning and operating combined wind-storage system in electricity market. IEEE Trans. Sustain. Energy 2012, 3, 209-217. [CrossRef]

28. Reuter, W.H.; Fuss, S.; Szolgayova, J.; Obersteiner, M. Investment in wind power and pumped storage in a real options model. Renew. Sustain. Energy Rev. 2012, 16, 2242-2248. [CrossRef] 
29. Delille, G.; Francois, B.; Malarange, G. Dynamic frequency control support by energy storage to reduce the impact of wind and solar generation on isolated power system's inertia. IEEE Trans. Sustain. Energy 2012, 3, 931-939. [CrossRef]

30. Such, M.C.; Hill, C. Battery energy storage and wind energy integrated into the Smart Grid. In Proceedings of the IEEE PES Innovative Smart Grid Technologies 2012, Washington, DC, USA, 16-20 January 2012.

31. Hu, P.; Karki, R.; Billinton, R. Reliability evaluation of generating systems containing wind power and energy storage. IET Gener. Transm. Distrib. 2009, 3, 783-791. [CrossRef]

32. Teleke, S.; Baran, M.E.; Bhattacharya, S.; Huang, A.Q. Optimal control of battery energy storage for wind farm dispatching. IEEE Trans. Energy Convers. 2010, 25, 787-794. [CrossRef]

33. Guesmi, T.; Farah, A.; Marouani, I.; Alshammari, B.; Hadj Abdallah, H. Chaotic sine-cosine algorithm for chance constrained economic emission dispatch problem including wind energy. IET Renew. Power Gener. 2020, 14, 1808-1821. [CrossRef]

34. Moazzami, M.; Ghanbari, M.; Moradi, J.; Shahinzadeh, H.; Gharehpetian, G.B. Probabilistic SCUC considering implication of compressed air energy storage on redressing intermittent load and stochastic wind generation. Int. J. Renew. Energy Res. 2018, 8, 767-783.

35. Teleke, S.; Baran, M.E.; Huang, A.Q.; Bhattacharya, S.; Anderson, L. Control strategies for battery energy storage for wind farm dispatching. IEEE Trans. Energy Convers. 2009, 24, 725-732. [CrossRef]

36. Alham, M.H.; lshahed, M.; Ibrahim, D.K.; Abo El Zahab, E. A dynamic economic emission dispatch considering wind power uncertainty incorporating energy storage system and demand side management. Renew. Energy 2016, 96, 800-811. [CrossRef]

37. Sundar, K.; Nagarajan, H.; Roald, L.; Misra, S.; Bent, R.; Bienstock, D. Chance-Constrained Unit Commitment with N-1 Security and Wind Uncertainty. IEEE Trans. Control. Netw. 2019, 6, 1062-1074. [CrossRef]

38. Vrakopoulou, M.; Li, B.; Mathieu, J.L. Chance Constrained Reserve Scheduling Using Uncertain Controllable Loads Part I: Formulation and Scenario-Based Analysis. IEEE Trans. Smart Grid 2019, 10, 1608-1617. [CrossRef]

39. Atta Mills, E.F.E.; Yu, B.; Gu, L. On meeting capital requirements with a chance-constrained optimization model. SpringerPlus 2016, 5, 500. [CrossRef]

40. Pagnoncelli, B.; Ahmed, S.; Shapiro, A. Sample average approximation method for chance constrained programming: Theory and applications. J. Optim. Theory Appl. 2009, 142, 399-416. [CrossRef]

41. Liu, X.; Xu, W. Economic load dispatch constrained by wind power availability: A here-and-now approach. IEEE Trans. Sustain. Energy 2010, 1, 2-9. [CrossRef]

42. Saravanan, B.; Kumar, C.; Kothari, D.P. A solution to unit commitment problem using fire works algorithm. Int. J. Electr. Power 2016, 77, 221-227. [CrossRef]

Publisher's Note: MDPI stays neutral with regard to jurisdictional claims in published maps and institutional affiliations.

(C) 2020 by the authors. Licensee MDPI, Basel, Switzerland. This article is an open access article distributed under the terms and conditions of the Creative Commons Attribution (CC BY) license (http://creativecommons.org/licenses/by/4.0/). 